\title{
Towards a Better Modelling and Assessment of Project Management Maturity in Industry 4.0
}

\author{
Felipe Sanchez ${ }^{1(\bowtie)}$, Davy Monticolo ${ }^{2}$, Eric Bonjour ${ }^{2}$, \\ and Jean-Pierre Micaëlli ${ }^{3}$ \\ ${ }^{1}$ Sopra Steria, Université de Lorraine, ERPI, 5 Place de L'Iris, \\ 92400 Courbevoie, France \\ felipe.sanchez@soprasteria.com \\ ${ }^{2}$ Université de Lorraine, ERPI, 8 Rue Bastien-Lepage, Nancy 54000, France \\ \{davy.monticolo, eric.bonjour\}@univ-lorraine.fr \\ 3 Jean Moulin Lyon 3 University, IAE Lyon School of Management, 1C avenue \\ des frères Lumière, CS 78242, 69372 Lyon Cedex 08, France \\ jean-pierre.micaelli@univ-lyon3.fr
}

\begin{abstract}
Companies are currently facing substantial challenges with regard to Industry 4.0. In order to adapt to this changing environment, companies are moving from operations-centered business to project-driven business. This change requires an evolution in project management. Researchers and practitioners, inspired by the PMBOK (Project Management Body of Knowledge), have created maturity models to compare and evaluate organizations, but they did not specify any methodology to create adapted models to face this technological change. Therefore, this paper proposes an approach to understand under on principles existing project management maturity models were based, and how it is possible to create a new project management maturity model applicable in the emerging framework of industry 4.0. Then, we illustrate the new approach with the construction of a project maturity model used to measure the planning capability. Finally, we define limitations of the model and future research directions.
\end{abstract}

